\title{
Interactions between retinol, $\alpha$-tocopherol and cholecalciferol need consideration in diets for farmed mink (Mustela vison)
}

\author{
Lone Hymøller $^{1 *}$, Tove N. Clausen ${ }^{2}$ and Søren K. Jensen ${ }^{1}$ \\ ${ }^{1}$ Department of Animal Science, Aarbus University, Blichers Allé 20, DK-8830 Tjele, Denmark \\ ${ }^{2}$ Copenhagen Fur Research Centre, Herningvej 112 C, DK-750O Holstebro, Denmark \\ (Submitted 22 June 2015 - Final revision received 30 November 2015 - Accepted 4 December 2015)
}

\section{Abstract}

A sufficient but balanced vitamin supplementation is a prerequisite for a satisfactory growth pattern and an effective immune system in mink and all other species. The fat-soluble vitamins are very sensitive to over- or under-supply because they interact with each other with respect to dose-response and chemical form. The purpose of the present study was to investigate the effect of increasing the amount of retinol in combination with RRR- $\alpha$-tocopherol or all-rac- $\alpha$-tocopherol in the feed given to growing mink on their retinol, cholecalciferol and $\alpha$-tocopherol concentrations in plasma and selected organs. The results showed that the mink met their retinol requirements from the basal diet, but there were no negative effects of supplying various amounts of retinol on their plasma $\alpha$-tocopherol concentrations. On the other hand, the study showed that the cholecalciferol status in plasma, assessed as the 25-hydroxycholecalciferol concentration, was low when retinol was supplemented in the feed at high levels. In addition, supplementation with RRR- $\alpha$-tocopherol in the feed negatively affected the plasma concentration of 25 -hydroxycholecalciferol compared with supplementation with all-rac- $\alpha$-tocopherol. In general, female mink had higher concentrations of fat-soluble vitamins in plasma than male mink.

Key words: Fat-soluble vitamins: Retinol: $\alpha$-Tocopherol: Cholecalciferol: Interactions: Mink

Traditionally, mink rations have been supplemented with relatively large amounts of fat-soluble vitamins ${ }^{(1)}$, compared with rations for other species, owing to the risk of vitamin losses in the perishable ingredients of mink diets (e.g. offal from the fishing industry and abattoirs). Improved chemical stability of commercial vitamin mixtures, improved mixing, transport and storage conditions of feed rations as well as the inclusion of large amounts of pig and poultry slaughter offal in mink rations during recent years have increased the risk of over-supplying mink with fat-soluble vitamins. Over-supply of fat-soluble vitamins, particularly with retinol (RET), increases the risk of liver damage and has in several species been shown to negatively affect the bioavailability of cholecalciferol (vitamin $\mathrm{D}_{3}$ (VD3)) and $\alpha$-tocopherol (TOC) ${ }^{(2-5)}$.

A sufficient and balanced supplementation with fat-soluble vitamins is vital to secure satisfactory growth and an effective immune system in mink and other species ${ }^{(6)}$. The fat-soluble vitamins RET, VD3 and TOC are particularly sensitive to over- or under-supply in the diet, because these vitamins have been shown to interact heavily in vivo and in vitro with respect to dose-response and chemical properties ${ }^{(2,3,7)}$.

RET, VD3 and TOC are complex substances involved in many physiological functions in the body. RET is required for various biological processes including vision, function of epithelial surfaces and the immune system, reproduction and normal embryonic development ${ }^{(8)}$. VD3 is involved in processes ranging from maintaining $\mathrm{Ca}$ homoeostasis in plasma and bones to modulating the function of the immune system ${ }^{(9,10)}$. However, to become physiologically active, VD3 must be hydroxylated first in the liver to 25-hydroxycholecalciferol (25VD3), which is the main VD3 metabolite in plasma and the form measured as an indicator of physiological VD3 status, and later in the kidneys to the physiologically active metabolite 1,25-dihydroxycholecalciferol. TOC acts as an antioxidant in the body and is very important for the development and functionality of the immune system ${ }^{(11)}$. It exists in eight different isomeric configurations: four (RSS, RRS, RRR, RSR) with 2R configuration and four (SRR, SRS, SSR, SSS) with $2 S$ configuration. The RRR isomer is the form of TOC that occurs in nature ${ }^{(6)}$, whereas TOC used for feed additives consists of a racemic mixture (all-rac) of all eight stereoisomers. In commercial vitamin mixtures, all-rac-TOC is typically acetylated, in order to stabilise its functional phenol group during storage and feed processing (pelleting, etc.), and therefore is added to rations as all-rac- $\alpha$-tocopheryl acetate. The acetate group must be hydrolysed before the TOC can be absorbed from the gastrointestinal tract ${ }^{(12)}$. According to the officially accepted biopotency factor observed in rats, RRR-TOC is 1.49 times more active than all-rac- $\alpha$-tocopheryl acetate ${ }^{(13)}$. However, in humans, only

Abbreviations: 25VD3, 25-hydroxycholecalciferol; RET, retinol; TOC, $\alpha$-tocopherol; VD3, cholecalciferol.

* Corresponding author: L. Hymøller, fax +45 871502 01, email Lone.Hymoller@anis.au.dk 
TOC with $2 \mathrm{R}$ configuration is considered biologically active $\mathrm{e}^{(14)}$. Jensen \& Lauridsen ${ }^{(15)}$ showed that mink, like humans, almost completely exclude TOC with the $2 \mathrm{~S}$ configuration from circulation, and Blatt et al. ${ }^{(16)}$ showed that the relative biopotency of RRR-TOC and all-rac-TOC varied with dosage. To counterbalance these discrepancies in the present experiment, it was decided to add the same amount of natural and synthetic TOC on molecular basis.

Interactions between RET, VD3 and the different stereoisomers of TOC are described in several species. For instance, supplementation with large doses of RET has been shown to negatively affect the bioavailability of TOC in growing pigs ${ }^{(17,18)}$ and calves ${ }^{(4)}$. RET supplementation has been shown to affect the bioavailability of VD3 in both humans ${ }^{(5,19)}$ and poultry ${ }^{(2,3)}$, which has led to the conclusion that the ratio of RET:VD3 seems to be more important than the actual concentrations of the vitamins in the diet ${ }^{(5,19,20)}$. The aim of the present study was to elucidate the risk of over-supplementing mink with RET and study the interactions between RET, VD3 and TOC in this species.

\section{Methods}

The present study complied with the Danish Ministry of Justice Law no. 1306 (23 November 2007) concerning experiments with animals and care of animals used for experimental purposes, and was conducted with the approval of the Danish Veterinary and Food Administration under the Danish Ministry of Food, Agriculture and Fisheries. The study was carried out at the Copenhagen Fur Research Centre in Holstebro, Denmark, between 1 July and 15 September 2010.

\section{Animals, housing and feeding}

A total of 110 male and female brown mink kits (Mustela vison) were used for the study. Littermates were housed pairwise (one male and one female) in cages from 2 weeks before the start of the study. All animal facilities were sheltered under permanent outdoor sheds with no sunlight access. The basic ration was a wet mink feed ration. The composition of this ration as fed is shown in Table 1. For each treatment group, $180 \mathrm{~kg}$ of the basic ration was supplemented with TOC, RET and VD3 according to the treatment plan and stored at $-18^{\circ} \mathrm{C}$ in $5-\mathrm{kg}$ bags. One bag per day was thawed and fed to the respective treatment group during the study period. The mink were fed once a day and had ad libitum access to water.

\section{Treatments and design}

The study was carried out as a longitudinal dose-response study with $100 \mathrm{mg} / \mathrm{kg}$ feed per d of either RRR-TOC or all-rac-TOC and different amounts of RET added to the feed between treatment groups. Before the study period, mink were placed in pairs (one male and one female) in cages for 2 weeks to habituate them to each other and to their housing facilities. At the beginning of the study, mink were weighed and started on the basic ration without added RET, TOC and VD3, and were maintained on this diet for 4 weeks to minimise their stores of fat-soluble vitamins and decrease the variability between animals. The natural
Table 1. Composition of basic ration as fed

\begin{tabular}{lc}
\hline Ingredients & $\%$ \\
\hline Poultry offal & $21 \cdot 7$ \\
Industrial fish & $20 \cdot 3$ \\
Water & $12 \cdot 4$ \\
Fish offal & $9 \cdot 5$ \\
Heat-treated barley & $7 \cdot 4$ \\
Heat-treated wheat & $7 \cdot 4$ \\
Fish silage & $7 \cdot 2$ \\
Lard & $4 \cdot 1$ \\
Meat meal & $3 \cdot 4$ \\
Maize gluten & $3 \cdot 4$ \\
Soya oil & $2 \cdot 1$ \\
Blood meal & $1 \cdot 0$ \\
Vitamin B mix* & $0 \cdot 1$ \\
DM (\%) & 44 \\
Energy (MJ/kg) & $8 \cdot 5$ \\
Energy distribution $\dagger$ & $30: 52: 18$ \\
\hline
\end{tabular}

* Vitral B-mink super (Agro Korn A/S). B $3000 \mathrm{mg} / \mathrm{kg} ; B_{2} 6000 \mathrm{mg} / \mathrm{kg} ; B_{6} 5000 \mathrm{mg} / \mathrm{kg}$; folic acid $1000 \mathrm{mg} / \mathrm{kg} ; B_{12} 20 \mathrm{mg} / \mathrm{kg} ;$ D-pantothenic acid $15000 \mathrm{mg} / \mathrm{kg} ;$ biotin $200 \mathrm{mg} / \mathrm{kg}$; choline chloride $100000 \mathrm{mg} / \mathrm{kg}$.

† Protein:fat:carbohydrates.

concentrations of RET and TOC in the diets were analysed three times in July in duplicate each time and averaged to 0.29 (sE 0.12) $\mathrm{mg} / \mathrm{kg}$ feed (972 (sE 402) IU/kg) for RET and 22 (sE 3$) \mathrm{mg} / \mathrm{kg}$ feed for TOC. VD3 was not analysed in the feed. Subsequently, the mink were weighed and randomly assigned to eleven treatment groups with ten mink per treatment. One group - group 0 - was euthanised immediately using $\mathrm{CO}_{2}$, which was considered the control group. The remaining groups 1-10 were treated as follows: groups $1-5$ received $100 \mathrm{mg}$ all-rac-TOC/kg feed and groups 6-10 received $100 \mathrm{mg}$ RRR-TOC/kg feed daily. In addition to the added TOC, groups 1 and 6 received 0 IU RET/kg feed, groups 2 and 7 received $1500 \mathrm{IU} \mathrm{RET} / \mathrm{kg}$ feed, groups 3 and 8 received $3000 \mathrm{IU}$ RET/kg feed, groups 4 and 9 received $4500 \mathrm{IU}$ RET $/ \mathrm{kg}$ feed and groups 5 and 10 received $6000 \mathrm{IU}$ RET/kg feed daily. All feed rations were supplemented with $700 \mathrm{IU}$ VD3/kg feed. RET was added as all-trans-retinyl acetate, all-rac-TOC was added as all-rac- $\alpha$-tocopheryl acetate, RRR-TOC was added as ImmunE ${ }^{\circledR}$ Natur (Agro Korn A/S) and VD3 was added as pure cholecalciferol (Agro Korn A/S). All vitamins were kindly provided by Agro Korn A/S. Mink in treatment groups 1-10 were weighed and euthanised using $\mathrm{CO}_{2}$ after 4 weeks of study. The TOC concentration of the experimental diets was analysed in duplicate for each of the ten experimental groups and presented as the mean concentration of each source ( $n$ 5). RET concentrations in the two diets not supplemented with RET were analysed in duplicate, and the results are presented as the mean concentration of these two diets.

\section{Sample material}

Feed intakes were measured by weighing refusals, and feed samples were collected once per study period and on the last day of the study. After euthanasia, blood samples were extracted from all mink using a syringe by heart puncture and placed in sodium heparin-coated sample tubes and left on ice to cool. Blood samples were centrifuged at $2000 \boldsymbol{g}$ for $10 \mathrm{~min}$ to 
isolate the plasma. Liver and kidneys from all mink were removed, weighed and placed on ice. The gall bladder was punctured, and its contents were removed before weighing the liver. All plasma and organ samples were subsequently stored at $-18^{\circ} \mathrm{C}$ until analysis.

\section{Chemical analyses}

Chemical analyses were performed at the Department of Animal Science, Aarhus University. All the samples and standard vitamin solutions were protected from light during preparation. Plasma, feed and organ concentrations of RET and TOC were determined as described by Jensen et al. ${ }^{(21)}$. The stereochemical composition of TOC in plasma and liver was determined after methylation of TOC stereoisomers into their methyl esters and subsequent separation by chiral HPLC as described by Jensen et al. ${ }^{(22)}$. Plasma concentrations of 25VD3 and VD3 were determined as described by Hymøller \& Jensen $^{(23)}$. In summary, after precipitation of proteins in ethanol and methanol, saponification of TAG in potassium hydroxide and extraction of fat-soluble vitamins in heptane, samples were dried using $\mathrm{N}_{2}$ and the residues were re-dissolved in $85 \%$ methanol. Separation and quantification of the vitamins were carried out by reverse-phase gradient HPLC and UV-detection at $265 \mathrm{~nm}$, using $1 \alpha$-hydroxycholecalciferol (Sigma-Aldrich) as the internal standard. Organ samples were homogenised by Ultra Turrax (IKA Labortechnik) in an ice bath and, as plasma and feed samples, were precipitated in ethanol and methanol, saponified with potassium hydroxide and extracted in heptane. Separation and quantification were carried out by HPLC as described by Jensen et $a l .{ }^{(21)}$.

\section{Statistical analyses}

ANOVA was performed using the MIXED models procedure of $\mathrm{SAS}^{\circledR}$ (SAS Institute). The statistical model used was $Y_{i j k l}=$ $\mu+\alpha_{i}+\beta_{j}+(\alpha \beta)_{i j}+\lambda_{k}+g_{i j k l}+e_{i k j l}$, where $Y_{i j k l}$ is the dependent variable, $\mu$ the overall mean, $\alpha_{i}$ the fixed effect of RET concentration $i$ in the feed $(0,1500,3000,4500,6000 \mathrm{IU} / \mathrm{kg}$ feed), $\beta_{j}$ the fixed effect of TOC source $j$ in the feed (RRR-TOC, all-rac-TOC), $(\alpha \beta)_{i j}$ the effect of the interaction between RET concentration $i$ and TOC source $j$ in the feed, $\lambda_{k}$ the fixed effect of animal sex $k$ (male, female), $g_{i j k l}$ the random effect of group $l$ and $e_{i j k l}$ the random residual error. To test for any effect of interaction between RET level in the feed, TOC source in the feed and sex of the mink, this interaction was initially included in the model but subsequently removed because of there being no significant effects. When comparing male and female mink in the control group 0 , only sex was included in the model. The linear relation between liver concentrations of RET and feed concentrations of RET and plasma concentrations of TOC and feed concentrations of RET was estimated using the REQ procedure of the SAS ${ }^{\circledR}$ system. Random effects were assumed to be normally distributed with a mean value of 0 and constant variance of $g_{i j k l} \sim N\left(0, \sigma_{g}^{2}\right)$ and $e_{i k j l} \sim N\left(0, \sigma^{2}\right)$. Differences were considered statistically significant when $P \leq 0.05$ and as tendencies if $0.05<P \leq 0 \cdot 10$. Results of the statistical analysis are presented as least squares mean with their standard error of the mean.

\section{Results}

Male mink in the control group 0 weighed 1768 (SE 135) g and female mink weighed 1200 (SE 121) g when euthanised before the study period. Plasma and liver concentrations of RET, $25 \mathrm{VD} 3, \mathrm{TOC}$ and stereoisomers of TOC in control group 0 are shown in Table 2. Plasma RET concentrations were higher in female mink than in male mink $(P=0.03)$, but no other significant differences were found at this point. At euthanasia, after the study period, male mink weighed on average 2577 (sE 37) g and female mink 1500 (sE 37) g. Male mink grew on average 769 (sE 74) g and female mink 319 (sE 48) g during the study period. The natural RET concentration in the basic ration during the study period was 3525 (sE 554) IU/kg feed. The concentration of TOC in the diets given to the all-rac-TOC group was 91 (SE 8) $\mathrm{mg} / \mathrm{kg}$ feed and that in the diets given to the RRR-TOC group was 93 (sE 33) $\mathrm{mg} / \mathrm{kg}$ feed. Feed consumption, weight of the mink and growth rate were not significantly affected by adding RET and TOC to the ration. The average feed consumption was 6.3 (SE 1.9) kg/mink during the study period.

The RET concentration in plasma was higher in female mink than in male mink $(P \leq 0 \cdot 001)$, and plasma concentrations of RET tended to increase with increasing amounts of added RET to the feed $(P=0.06)$. However, the plasma RET concentration was not significantly affected by whether RRR-TOC or all-rac-TOC was added to the feed along with RET $(P=0 \cdot 12)$ (Table 3$)$. The plasma concentration of 25VD3 was lower when the RET concentration in the feed was high $(P \leq 0 \cdot 001)$, and was higher in mink receiving all-rac-TOC in the feed than in mink receiving RRR-TOC in the feed $(P \leq 0.001)$. Therefore, the plasma 25VD3 concentration was the highest when RET in the feed was low and all-rac-TOC was added to the feed, and was the lowest

Table 2. Plasma, liver and kidney concentrations of retinol (RET), 25-hydroxycholecalciferol (25VD3) and a-tocopherol (TOC) and TOC stereoisomers in plasma and liver in male and female mink in the control group 0

(Least square mean values with their standard errors of means; $n$ )

\begin{tabular}{|c|c|c|c|c|}
\hline & \multicolumn{2}{|c|}{ Sex } & \multirow[b]{2}{*}{ SEM } & \multirow[b]{2}{*}{$P$} \\
\hline & Male & Female & & \\
\hline \multicolumn{5}{|l|}{ Plasma } \\
\hline $\operatorname{RET}(\mu \mathrm{mol} / \mathrm{l})$ & 5.99 & 9.50 & 1.35 & 0.03 \\
\hline 25VD3 (nmol/l) & 129 & 146 & 17 & 0.37 \\
\hline TOC $(\mu \mathrm{mol} / \mathrm{l})$ & $30 \cdot 6$ & 35.4 & 8.9 & 0.60 \\
\hline $2 \mathrm{~S}(\mu \mathrm{mol} / \mathrm{l})$ & 0.9 & 0.8 & 0.2 & 0.51 \\
\hline $\mathrm{RSS}(\mu \mathrm{mol} / \mathrm{l})$ & $2 \cdot 0$ & $2 \cdot 4$ & 0.8 & 0.61 \\
\hline $\mathrm{RRS}(\mu \mathrm{mol} / \mathrm{l})$ & 4.6 & 5.4 & $1 \cdot 2$ & 0.53 \\
\hline $\mathrm{RRR}(\mu \mathrm{mol} / \mathrm{l})$ & $20 \cdot 9$ & $24 \cdot 4$ & $6 \cdot 1$ & 0.59 \\
\hline RSR $(\mu \mathrm{mol} / \mathrm{l})$ & $2 \cdot 2$ & 2.4 & 0.7 & 0.71 \\
\hline \multicolumn{5}{|l|}{ Liver } \\
\hline RET $(\mathrm{nmol} / \mathrm{g})$ & 1676 & 2529 & 507 & 0.14 \\
\hline $\mathrm{TOC}(\mathrm{nmol} / \mathrm{g})$ & $26 \cdot 4$ & $30 \cdot 1$ & 6.9 & 0.61 \\
\hline $2 S(\mathrm{nmol} / \mathrm{g})$ & $6 \cdot 1$ & 6.5 & 1.5 & 0.79 \\
\hline RSS (nmol/g) & 1.4 & 1.9 & 1.0 & 0.66 \\
\hline RRS (nmol/g) & 3.5 & 4.6 & $1 \cdot 2$ & 0.39 \\
\hline RRR (nmol/g) & $14 \cdot 3$ & $15 \cdot 8$ & $3 \cdot 8$ & 0.72 \\
\hline RSR (nmol/g) & $1 \cdot 1$ & 1.3 & 0.6 & 0.70 \\
\hline \multicolumn{5}{|l|}{ Kidneys } \\
\hline RET $(\mathrm{nmol} / \mathrm{g})$ & 1395 & 1082 & 337 & 0.39 \\
\hline TOC $(\mathrm{nmol} / \mathrm{g})$ & $22 \cdot 6$ & $22 \cdot 2$ & $5 \cdot 0$ & 0.95 \\
\hline
\end{tabular}


when RET in the feed was high and RRR-TOC was added to the feed (Table 3). Plasma concentrations of 25VD3 were the highest $(274 \mathrm{nmol} / 1 ; P \leq 0 \cdot 05)$ at a RET:VD3 ratio of $4 \cdot 29: 1$ in the feed, calculated on an IU basis. The corresponding RET concentration was $10 \cdot 12 \mu \mathrm{mol} / 1$ (Table 4 ). Sex of the mink had no significant effect on plasma levels of 25VD3 $(P=0.57)$.

Overall, the concentration of TOC in plasma was unaffected by the RET concentration of the feed $(P=0.63)$ and no interaction was observed, but plasma TOC concentrations were higher in mink receiving RRR-TOC in the feed than in those receiving all-rac-TOC ( $P \leq 0 \cdot 01)$ (Table 3$)$. However, a separate regression analysis of each of the two TOC sources showed a linear increase in TOC concentration for all-rac-TOC with increasing RET concentration in the feed $\left(R^{2} 0.96 ; P \leq 0.01\right)$. This increase was mainly caused by a relative increase in RRR-TOC, whose relative contribution increased linearly from 43 to $48 \%$ of all TOC stereoisomers with increasing RET concentration in the feed $(P=0 \cdot 03)$. Again female mink had a higher TOC concentration in plasma than male mink $(P \leq 0 \cdot 01)$. Concentrations of RRR-TOC in plasma were higher in mink receiving RRR-TOC in the feed than in mink receiving all-rac-TOC $(P \leq 0 \cdot 001)$, whereas concentrations of other stereoisomers of TOC were higher in mink receiving all-rac-TOC in the feed than in mink receiving RRR-TOC $(P \leq 0.001)$ (Table 3).

Organ weights were similar among groups, and on average the weight of the liver was 3.3 (SE 0.6 ) $\mathrm{g} / 100 \mathrm{~g}$ mink and the weight of both kidneys was 0.5 (sE 0.1$) \mathrm{g} / 100 \mathrm{~g}$ mink. RET concentrations in the liver tended to be affected by the RET concentration of the feed $(P=0.05)$ (Table 5$)$ and as an average of all mink increased linearly with increasing feed RET concentrations $\left(P \leq 0.001 ; R^{2}\right.$ 0.98). There was no significant effect of TOC source in the feed on liver RET concentrations (Table 5), but female mink had higher liver RET concentrations than males $(P \leq 0.05)$. RET concentrations of the kidneys were unaffected by the RET concentration in the feed, but were generally higher in mink receiving RRR-TOC than in those receiving all-rac-TOC ( $P \leq 0 \cdot 01)$, except for the 1500 IU group, which resulted in a significant interaction between RET and TOC in the feed $(P \leq 0.05)$. Male mink had higher RET concentrations in the kidneys compared with female mink $(P \leq 0 \cdot 001)$.

The level of RET in the feed had no significant effect on TOC levels in the kidneys and liver (Table 5). TOC concentrations were higher in the kidneys of mink receiving RRR-TOC than in those receiving all-rac-TOC in the feed $(P \leq 0.05)$. In contrast, TOC concentrations in the liver were higher in mink receiving all-rac-TOC compared with mink receiving RRR-TOC $(P \leq 0.001)$. In the liver, 2S-TOC accounted for $45 \%$ of total TOC, whereas RRR-TOC only accounted for $24 \%$ of total TOC in the liver of mink fed all-rac-TOC. RRR-TOC accounted for $95 \%$ of total TOC in livers from mink fed RRR-TOC. In general, female mink had higher TOC concentrations in the liver $(P \leq 0.01)$ and tended to have higher TOC concentrations in the kidneys than male mink $(P=0 \cdot 07)$. Concentrations of stereoisomers of TOC in the liver were unaffected by the RET concentration in the feed, and no interactions between RET concentration and TOC source in the feed were observed. 
Table 4. Plasma concentrations of 25-hydroxycholecalciferol (25VD3) and retinol (RET) in relation to the RET:cholecalciferol (VD3) ratio in the feed (Least square mean (LSM) values with their standard errors of means; $n$ 10)

\begin{tabular}{|c|c|c|c|c|c|}
\hline & & & & & SEM \\
\hline RET in feed* & 1500 (IU/kg) & 3000 (IU/kg) & 4500 (IU/kg) & $6000(\mathrm{IU} / \mathrm{kg})$ & \\
\hline VD3 in feed $t$ & 700 (IU/kg) & $700(\mathrm{IU} / \mathrm{kg})$ & $700(\mathrm{IU} / \mathrm{kg})$ & $700(\mathrm{IU} / \mathrm{kg})$ & \\
\hline RET:VD3 ratio in feed (IU) & $2 \cdot 14: 1$ & $4 \cdot 29: 1$ & 6.43:1 & $8 \cdot 57: 1$ & \\
\hline \multicolumn{6}{|l|}{ Plasma } \\
\hline 25VD3 (nmol/l) & $237^{a, b}$ & $274^{\mathrm{a}}$ & $231^{\mathrm{b}}$ & $188^{\mathrm{C}}$ & 14 \\
\hline $\mathrm{RET}(\mu \mathrm{mol} / \mathrm{l})$ & $7 \cdot 75$ & $10 \cdot 12$ & 9.04 & 9.74 & 0.87 \\
\hline
\end{tabular}

a,b,c LSM values within a row with unlike superscript letters were significantly different $(P \leq 0.05)$.

* All-trans-RET acetate added to the feed.

† Added as pure VD3.

\section{Discussion}

The natural concentration of RET in the feed was higher than that expected during the study period, probably due to the large amounts of poultry and fish offal used, which contain various amount of entrails including liver, and therefore a certain amount of RET in the form of retinyl palmitate. The TOC concentration corresponded to the added amounts. Adding RRR-TOC to the rations appeared to cause a larger variation in TOC concentrations of the rations than adding all-rac-TOC, probably due to mixing technicalities. Feed consumption and growth rate of the mink were similar among treatment groups, probably because none of the treatment groups experienced RET deficiency due to the high natural RET concentration of the feeds.

The lower variability in body weight between animals and sexes at the beginning of the study compared with the end of the study may be related to a relatively higher growth rate of the mink at the beginning of the study than by the end of the study. A high growth rate emphasises differences between animals in general, and between males and females, owing to a higher growth rate in males than in females. The differences between male and female mink in concentrations of fat-soluble vitamins in plasma and organs are most likely related to differences in feed consumption, growth rate and feed utilisation between sexes. However, no reliable data supporting this are available, because mink are typically housed one male and one female together during the growth season to avoid aggressive behaviour.

In species other than mink, supplementing diets with large doses of RET has been shown to negatively affect the bioavailability of TOC. In growing pigs, Ching et $a l .{ }^{(17)}$ found a negative impact on serum and liver TOC concentrations from increasing dietary levels of RET from 2200 to $13200 \mathrm{IU} / \mathrm{kg}$, regardless of whether 15 or $90 \mathrm{IU} / \mathrm{kg}$ RRR-TOC or all-rac-TOC was supplemented in the feeds. In pigs fed a diet containing approximately $110 \mathrm{mg} / \mathrm{kg}$ TOC and either $100000 \mathrm{IU}$ RET/kg diet or $0 \mathrm{IU} \mathrm{RET} / \mathrm{kg}$ diet, the liver concentrations of TOC were significantly lower in pigs fed the diet high in RET than in pigs fed the diet low in RET ${ }^{(18)}$. Moreover, in calves, feeding large amounts of RET was associated with reduced plasma levels of RRR-TOC ${ }^{(4)}$. The physiological explanation behind this apparent antagonistic relation between RET and TOC is unknown; however, in rat liver, RET has been shown to suppress gene expression of proteins related to the formation of carriers of RRR-TOC (e.g. lipoproteins in plasma) ${ }^{(24,25)}$. In cell cultures modelling intestinal epithelium with Caco-2 cells, Goncalves et al. ${ }^{(7)}$ showed that both RET and VD3 added to the cell medium reduced the uptake of TOC in a dose-dependent manner. The enzyme (carboxyl ester hydrolase) responsible for hydrolysing the ester of TOC has been shown in in vitro studies to be noncompetitively inhibited by RET-acetate ${ }^{(26)}$. In the present study, the RET concentration in the feed had no effect on TOC concentrations in plasma, liver or kidneys, regardless of the type of TOC supplied to the mink. There are several possible explanations for this finding: as a carnivore, mink may be biologically suited to handling large amounts of RET originating from their prey, or the carboxyl ester hydrolase enzyme activity may not be a limiting factor in mink. A similar lack of antagonistic relation between RET and TOC has been previously shown in humans, where the RET concentration in plasma - as an indicator of RET nutritional status - had no correlation to TOC levels in plasma in lactating women, whereas TOC levels in the colostrum correlated negatively to the plasma RET concentration ${ }^{(27)}$.

Supplementing the mink in the present study with RRR-TOC gave rise to a higher concentration of TOC in plasma and kidneys than supplementing with all-rac-TOC, which on the other hand caused a higher TOC concentration in the liver. In growing male mink kits, it was previously shown that plasma and liver concentrations of RRR-TOC decreased throughout the entire weaning period in RRR-TOC-supplemented mink, whereas concentrations of 2S-isomers of TOC increased in all-rac-TOC-supplemented mink ${ }^{(28)}$. Furthermore, serum and liver TOC concentrations in growing pigs were found by Chung et al. ${ }^{(29)}$ to be higher when RRR-TOC was used as a feed additive than when all-rac-TOC was used in amounts between 16 and $96 \mathrm{IU} / \mathrm{kg}$ feed. This is probably because the synthetic isomers of all-rac-TOC are accumulated in the liver, owing to the preference of TOC transfer protein ( $\alpha$-TTP) for secreting the natural RRR-stereoisomer of TOC into lipoproteins ${ }^{(30,31)}$. Il'ina et $a l .{ }^{(32)}$ found that the TOC concentration was higher in the kidneys than in the liver in both wild and farmed mink. However, the TOC supplementation of the farmed mink in their study was not provided; therefore, the opposite relation between TOC concentrations in the liver and the kidneys in the present study could be a consequence of the dose of TOC supplied in the feed in the two studies, respectively. The distribution of stereoisomers in the liver in the present study 
shows that the generally accepted ratio of 1:1.49 between all-rac-TOC and RRR-TOC in not applicable in mink, but to establish the ratio in mink a dose-response study with the two different TOC forms must be carried out.

In the present study, plasma concentrations of 25VD3 were lower in the treatment groups with the highest plasma concentrations of RET compared with treatment groups with lower plasma concentrations of RET. In broiler chickens, different studies have indicated that high dietary RET levels interfered with the bioavailability of VD3 and 25VD3, particularly when VD3 was supplied in low levels in the feed. On the other hand, RET did not affect the VD3 bioavailability when VD3 was synthesised endogenously in the skin of the birds from exposure to UV light or supplied at recommended levels in the feed $(2000-3000 \mathrm{IU} / \mathrm{kg} \text { feed })^{(2,3,33)}$. However, direct plasma concentrations of VD3 and 25VD3 were not analysed in these studies, but were assessed as biological activity of VD3 and expressed in terms of bone ash concentration.

In turkey poults fed diets high $(400000 \mathrm{IU} / \mathrm{kg})$ or low $(4000 \mathrm{IU} / \mathrm{kg})$ in RET and/or high $(900000 \mathrm{IU} / \mathrm{kg})$ or low (900 IU $/ \mathrm{kg}$ ) in VD3, where low was equivalent to the National Research Council recommendations and double-low was used as control, the bones of the animals failed to develop normally when RET was high and VD3 was low. In all other treatment groups, including the control group, bones developed normally. Therefore, it was speculated that the ratio between RET: VD3 in the diet was more important than the actual level of RET and VD3 in the diet ${ }^{(5,19,20)}$. Studies in rats have shown severe antagonistic effects of RET on VD3 with respect to normal serum $\mathrm{Ca}$ levels; however, in these studies, calculated ratios between RET:VD3 were very high between 30:1 and $30000: 1^{(34,35)}$, when applying the following conversion factors to reported results: VD3 $40 \mathrm{IU} / \mu \mathrm{g}$ and $\mathrm{RET} 3.3 \mathrm{IU} / \mathrm{\mu g}^{(5)}$. In many species, including humans, a RET:VD3 ratio between 4:1 and $7: 1$ is considered acceptable ${ }^{(5)}$. However, a ratio of approximately 10:1 is commonly applied in rations for most production animals. The rationale behind this is unknown, but results from the present study indicate that the RET:VD3 ratio needs further investigation. The physiological background for the antagonistic effect of RET on VD3 is unknown. It may be due to competition during uptake from the intestine, during incorporation into mixed micelles in lymph or during plasma transport of VD3 metabolites. Alternatively, it may be related to the liver's double function as a RET storage site and site of hydroxylation of VD3, because excessive amounts of RET stored in the liver could negatively affect the hydroxylation process of VD3. However, this aspect needs further investigation ${ }^{(20)}$.

In the studies by Aburto \& Britton ${ }^{(2,3)}$, increasing the supplementation of broiler chickens with all-rac-TOC had a negative impact on the biological activity of VD3, whereas in the present study the plasma concentrations of 25VD3 was lower when mink were supplemented with RRR-TOC than when supplemented with all-rac-TOC, regardless of the RET supplementation level in the feed. In cell cultures, Goncalves et $a l .{ }^{(7)}$ showed that the VD3 uptake was reduced when TOC was added to the cell medium. Goncalves et $\mathrm{al}^{(7)}$ argued that it was because VD3 and TOC share transport mechanisms in the intestine. This observation is supported by the present study 
where RRR-TOC supplementation had a more negative effect on plasma 25VD3 levels than supplementation with all-rac-TOC. RRR-TOC and all-rac-TOC are assumed to be absorbed equally in the intestines ${ }^{(36)}$, and thus the observed difference is most likely related to RRR-TOC binding more efficiently to $\alpha$-TTP in the liver than synthetic stereoisomers of TOC because of its biologically favoured conformation.

In conclusion, supplementing with the fat-soluble vitamins RET, VD3 and TOC in diets of mink gives rise to pronounced physiological interactions between the three fat-soluble vitamins in the body of the mink. Particularly, RET has a negative dose-dependent effect on plasma levels of 25VD3, but the RRR-stereoisomer of TOC seems to be involved heavily in regulatory processes controlling plasma and organ levels of RET as well. Interactions between RET, VD3 and TOC in general need further investigation in all species.

\section{Acknowledgements}

The authors thank the technical staff of the Copenhagen Fur Research farm in Holstebro, Denmark, and the laboratories at the Department of Animal Science at Aarhus University in Tjele, Denmark. Agro Korn A/S is acknowledged for kindly providing the vitamins used for the feed rations.

The study was supported by Copenhagen Fur and Aarhus University.

The authors' contributions are as follows: L. H. contributed to the laboratory analyses, data analysis, interpretation of the findings and writing the final manuscript. T. N. C. and S. K. J. contributed to formulating the research questions, study design, laboratory analyses, data analysis, interpretation of the findings and writing the final manuscript.

The authors have no conflicts of interest to declare.

\section{References}

1. Lassén TM (2010) Anbefaling - gældende - minkfoders sammensætning 2010 (Recommendation - current - formulation of mink diets 2010). Internal report. Copenhagen: Copenhagen Fur Advisory Centre.

2. Aburto A \& Britton WM (1998) Effects of different levels of vitamins $\mathrm{A}$ and $\mathrm{E}$ on the utilization of cholecalciferol by broiler chickens. Poult Sci 77, 570-577.

3. Aburto A \& Britton WM (1998) Effects and interactions of dietary levels of vitamins A and $\mathrm{E}$ and cholecalciferol in broiler chickens. Poult Sci 77, 666-673.

4. Ametaj BN, Nonnecke BJ, Franklin ST, et al. (2000) Dietary vitamin A modulates the concentrations of RRR- $\alpha$-tocopherol in plasma lipoproteins from calves fed milk replacer. $J$ Nutr 130, 629-636.

5. Linday LA, Umhau JC, Schindledecker RD, et al. (2010) Cod liver oil, the ratio of vitamins $\mathrm{A}$ and $\mathrm{D}$, frequent respiratory tract infections, and vitamin D deficiency in young children in the United States. Ann Otol Rhinol Laryngol 119, 64-70.

6. Kono N \& Arai H (2015) Intracellular transport of fat-soluble vitamins A and E. Traffic 16, 19-34.

7. Goncalves A, Roi S, Nowicki M, et al. (2015) Fat-soluble vitamin intestinal absorption: absorption sites in the intestine and interactions for absorption. Food Chem 172, 155-160.

8. Ross AC \& Harrison EH (2007) Vitamin A: nutritional aspects of retinoids and carotenoids. In Handbook of Vitamins, 4th ed. pp. 1-39 [J Zempleni, RB Rucker, DB McCormick, et al., editors]. London: CRC Press, Taylor \& Francis Group.

9. Braidman IP \& Anderson DC (1985) Extra-endocrine functions of vitamin D. Clin Endocrinol (Oxf) 23, 445-460.

10. Lips P (2006) Vitamin D physiology. Prog Biophys Mol Biol 92 , 4-8.

11. Nakamura YK \& Omaye ST (2009) Vitamin E-modulated gene expression associated with ROS generation. J Funct Foods 1, 241-252.

12. Jensen SK, Engberg RM \& Hedemann MS (1999) All-rac- $\alpha$-tocopherol acetate is a better vitamin E source than all-rac- $\alpha$-tocopherol succinate for broilers. I Nutr $\mathbf{1 2 9}$, $1355-1360$.

13. United States Pharmacopeial Convention (1979) 5th Supplement to the United States Pharmacopeia 19th edition and the National Formulary 14th edition. Rockville, MD: The United States Pharmacopeial Convention.

14. Food and Nutrition Board, Institute of Medicine (2000) Dietary Reference Intakes for Vitamin C, Vitamin E, Selenium, and Carotenoids. Washington, DC: National Academies Press.

15. Jensen SK \& Lauridsen C (2007) $\alpha$-Tocopherol stereoisomers. In Vitamin E, Vitamins \& Hormones, vol. 76, pp. 281-308 [G Litwack, editor]. San Diego, CA: Academic Press.

16. Blatt DH, Pryor WA, Mata JE, et al. (2004) Re-evaluation of the relative potency of synthetic and natural $\alpha$-tocopherol: experimental and clinical observations. J Nutr Biochem 15, 380-395.

17. Ching S, Mahan DC, Wiseman TG, et al. (2002) Evaluating the antioxidant status of weanling pigs fed dietary vitamins A and E. J Anim Sci 80, 2396-2401.

18. Olivares A, Rey AI, Daza A, et al. (2009) High dietary vitamin A interferes with tissue $\alpha$-tocopherol concentrations in fattening pigs: a study that examines administration and withdrawal times. Animal 3, 1264-1270.

19. Spiesman IG (1941) Massive doses of vitamins A and D in the prevention of the common cold. Arch Otolaryngol 34, $787-791$

20. Metz AL, Walser MM \& Olson WG (1985) The interaction of dietary vitamin A and vitamin D related to skeletal development in the turkey poult. $J$ Nutr 115, 929-935.

21. Jensen SK, Jensen C, Jakobsen K, et al. (1998) Supplementation of broiler diets with retinol acetate, $\beta$-carotene or canthaxanthin: effect on vitamin status and oxidative status of broilers in vivo and meat stability. Acta Agric Scand Sect A $\mathbf{4 8}$, 28-37.

22. Jensen SK, Nørgaard JV \& Lauridsen C (2006) Bioavailability of $\alpha$-tocopherol stereoisomers in rats depends on dietary doses of all-rac- or RRR- $\alpha$-tocopheryl acetate. Br J Nutr 95, 477-487.

23. Hymøller L \& Jensen SK (2011) Vitamin D analysis in plasma by high performance liquid chromatography (HPLC) with C(30) reversed phase column and UV detection - easy and acetonitrile-free. J Chromatogr A 1218, 1835-1841.

24. Zolfaghari R \& Ross AC (1994) Effect of vitamin A deficiency and retinoic acid repletion on intestinal and hepatic apolipoprotein A-1 mRNA levels of adult rats. J Lipid Res 35, 1985-1992.

25. Zolfaghari R \& Ross AC (1995) Chronic vitamin A intake affects the expression of mRNA for apolipoprotein A-I, but not for nuclear retinoid receptors, in liver of young and aging Lewis rats. Arch Biochem Biophys 323, 258-264.

26. Lauridsen C, Hedemann MS \& Jensen SK (2001) Hydrolysis of tocopheryl and retinyl esters by porcine carboxyl ester hydrolase is affected by their carboxyl moiety and bile acids. J Nutr Biochem 12, 219-224.

27. Lira LQ, Lima MSR, Mendeiros JMS, et al. (2013) Correlation of vitamin A nutritional status on alpha-tocopherol in the colostrum of lactating women. Matern Child Nutr 9, 31-40. 
28. Hedemann MS, Clausen TN \& Jensen SK (2011) Changes in digestive enzyme activity, intestine morphology, mucin characteristics and tocopherol status in mink kits (Mustela neovision) during the weaning period. Animal 5, 394-402.

29. Chung YK, Mahan DC \& Lepine AJ (1992) Efficacy of dietary D- $\alpha$-tocopherol and DL- $\alpha$-tocopheryl acetate for weanling pigs. J Anim Sci 70, 2485-2492.

30. Hosomi A, Arita M, Sato Y, et al. (1997) Affinity for $\alpha$-tocopherol transfer protein as a determinant of the biological activities of vitamin E analogs. FEBS Lett 409, 105-108.

31. Burton GW, Traber MG, Acuff RV, et al. (1998) Human plasma and tissue alpha-tocopherol concentrations in response to supplementation with deuterated natural and synthetic vitamin E. Am J Clin Nutr 67, 669-684.
32. Il'ina TN, Roukolainen TR \& Belkin VV (2008) Tocopherol content in tissues of mammals of different ecogenesis. $J$ Evol Biochem Physiol 44, 682-686.

33. Aburto A, Edwards HM \& Britton WM (1998) The influence of vitamin A on the utilization and amelioration of toxicity of cholecalciferol, 25-hydroxycholecalciferol, and 1,25 dihydroxycholecalciferol in young broiler chickens. Poult Sci 77, 585-593.

34. Rhode CM, Manatt M, Clagett-Dame M, et al. (1999) Vitamin A antagonizes the action of vitamin D in rats. J Nutr 129, 2246-2250.

35. Rhode CM \& DeLuca HF (2005) All-trans retinoic acid antagonizes the action of calciferol and its active metabolite, 1,25-dihydroxycholecalciferol, in rats. J Nutr 135, 1647-1652.

36. Borel P, Preveraud D \& Desmarchelier C (2013) Bioavailability of vitamin E in humans: an update. Nutr Rev 71, 319-331. 